\title{
Mechanism Design Considering the Aspect of Field Modeling Database
}

\author{
Mr. Santosh Kr. Pathak ${ }^{1}$, Dr. G.D. Mehta ${ }^{2}$, Mr. V.S. Shende ${ }^{3}$ \\ PG Student ${ }^{l}$, Associate Professor (Guide) $)^{2}$, Associate Professor (Co-Guide) ${ }^{3}$ \\ Priyadarshini College of Engineering, Nagpur.
}

DOI: 10.46335/IJIES.2020.5.10.8

\begin{abstract}
The Provided Research Paper elaborates the mechanism design by considering the modeling-based aspect of field data.
\end{abstract}

As first of all, this experimental theory was given by Hilbert Schenc Jr., where he explains it as an approach to representing the response of any job phenomenon in terms of proper interaction with the different input. This Field Database Modeling's main objective is to create a process by which the overall productivity of the Indented Pre Stressed Wire Manufacturing Industry would be easier to boost. With the correction of the available inputs to produce the output, this will all happen. The creation of this mechanism will make it easier to reduce expenditure on human energy,

When conducting the Manufacturing assembly of the indented strand wire. The main ergonomics \& workstation parameters that affect the productivity were established in this research study. Workstation dimensions, raw material dimensions, anthropometric employee data, employee energy Some parameters are specified for the spending and working conditions. Working conditions include ambient temperature, noise level, light intensity, air moisture, etc. And we then segregate from all these variables as dependent Variables and Independent Variables. As now, we noticed a large number of variables that were reduced into a few dimensionless variables by using dimensional analysis. The theorem of Buckingham pi is used to construct dimensional equations to explain relationships between dependent and independent terms. A mathematical Relationship is then formed.

Keywords- FDBM; Ergonomics; Dimensional analysis, Optimization; sensitivity analysis

\section{I- INTRODUCTION}

$\mathrm{F}$ man machine system [1]. It is the relationship between input and output variables. These types of modelling have been used to enhance device efficiency by recommending or changing inputs to improve output. As in all Production Plants, all operations include employees with a heavy use of Manual Labor, Includes Manuel Handling of Raw Materials All this induces stress and fatigue, which eventually decreases efficiency. A Generalized Mathematical Model can now be very useful for Choosing Optimized Input Variables in order to minimize Human Energy Consumption in order to increase overall productivity.

\section{II- SELECTION OF INDUSTRY}

Enterprise selected for study is a medium scale industry in Bokaro Industrial Area in Jharkhand. The industry is involved in fabrication of 3 Ply Indented Strand Wire, which is the base product for the manufacturing of Railway Sleepers.

\section{III- METHODOLOGY TO CARRY OUT THE FIELD DATA BASED MODEL}

In the case of Man Machine system for some of the activities such as Raw Material Processing for any kind of Finished Component Manufacturing, formulating the Quantitative Relationship for the Complex Phenomenon is not rational, as it is difficult to produce a theoretical model. So another choice we have is modelling based on 
experimental data, Hence it is proposed to formulate this Experimental data Based Modelling for the fabrication of $3 \times 3$ Ply indented strands wire. Now the Approach adopted for formulating generalized experimental model is suggested by Hilbert Schenck Jr. [2]. Is step wise detailed as below.

\section{IV-PLAN OF WORK}

Research starts with field work in the actual sector, where we research the new system or procedure an-d list the problems.

Here, too, we choose an appropriate input probability distribution for and input Considering the human and computer interaction phenomena, the process variables of the phenomenon would be unknown.

It also describes the cause and effect of qualitative results. Analysis. Also Causes or independent variables an Extraneous Variables.

On the basis of the process variable, less analysis of the process parameter will be done. As in $\mathrm{H}$ 's theory of engineering experimentation. Schenck Jr., Chapter 4 [10], The Option of Primary Dimensions. Most systems need at least three primary values, variables expressed in mass (M), length ( L), time ( $\mathrm{T}$ ) and thus $\mathrm{M}, \mathrm{L}$, and $\mathrm{T}$ are chosen for dimensional purposes.For dimensional analysis After the process variables are preserved, field data will be obtained. On the basis of field data, a mathematical model such as a productivity, human energy and system efficiency model will be created. The mathematical relationship between inputs and outputs could be of any form It can be polynomial, exponential or log linear. But here is The Theorem of Buckingham [8] found suitable for developing the model that can be represented by eqn. (1)

$\mathrm{Y}=\mathrm{K} \times \mathrm{Aa} \times \mathrm{Bb} \times \mathrm{Cc} \times \mathrm{Dd} \times \mathrm{Ee} \quad \ldots$ (1)

The optimum parameters will be calculated by setting the current value of the parameters in the defined model. In the light o-f these criteria, a new mechanism will be developed to minimise human energy and increase efficiency.

\section{V- PROBLEM IDENTIFICATION}

Presently the production task was carried out by the worker manually by actually imparting, stretching and feeding the wire rod through the die and finally to the drum (Tool) and thus producing small bobbins in terms of production, because of this use of huge no. of the manpower needed. It also affects productivity, as more time is required to do this. By the usage of this old coinvention. manual method the production achieved was very less and hardly have we to limit our production requirement to a minimum number.

\section{VI- LITERATURE REVIEW}

Formulation of Mathematical Model and Neural Network Analysis of Scheffler Reflector on the Scheffler reflector 's function, Rupesh Patil, Gajanan K. Awari and Mahendra P. Singh [7] had stated. The emphasis here was on the further development of experimental DBM in order to create uniqueness in other Scheffler reflector variables. The Scheffler reflector analysed the simultaneous variance of independent variables on a specific experimental plan. There, by formulating dimensional equations, experimental response data was analysed and validated using neural network analysis. Fall in liquor revenue in terms of various causes by applying field data based mathematical modelling

Satish Chaturvedi, Shubha Johri, J.P. Modak[10], identified that Pre Independence INDIA of the British regime, In the Central Provinces and Berar, specifically for the duration from June 1930 to September 1930, strong protests took place in Against reduction of Government revenue by way of Reducing liquor consumption. Model that correlates the decline in revenue from liquor in terms of different factors that are responsible for this fall in revenue. It is only through the Mathematical Model that we get a quantitative understanding of the degree of causes' interaction on the results of any phenomena, whether they are scientific or socioeconomic or of any other nature.

Sachin G Mahakalkar, Dr. Vivek H Tatwawadi, Jayant P Giri, Dr. J. P. Modak[12] submitted that Response Surface Methodology ( RSM) is a statistical approach that is useful in modelling and analysing problems where multiple independent variables influence the response variable to decide the conditions under which these variables should work to optimise a corrugated box .The main purpose of the research is to construct response surface models through regression on experimental data which has been reduced using DA to achieve optimal processing conditions. Independent parameters include anthropometric worker data, personal data, system specification, parameters of the workplace, product specification, environmental conditions and corrugated sheet mechanical properties. Modelling and simulation of human powered flywheel motor by field data-based modelling 
As per India 's geographical survey, A. R. Lende, J. P. Modak [13], studies show that approximately 65 percent of the human population lives in nonurban areas where urban services such as electricity, accessibility to jobs, etc. are very low. The nation with a greater population residing in villages should have research in areas that focus and make use of the tools available to the workforce. A pedal controlled human driven flywheel motor (HPFM) was developed as an energy source for process units by some authors related to this work. Most of the different process units tried to date are agricultural, such as brick making machines (both rectangular and keyed cross sections), low head water raising, wood turning, cutting wood strips, generating electricity, etc. The theory of HPFM was brought into existence in order to evaporate these energy disparities and irregularities. It was found at the time of its work that the productivity has great affection for the rider and has a tremendous impact on the product quality and quantity. This document takes a step forward in the development of a controller that eliminates machine ups and downs. Formulation of a Field Data Based Model for a Surface Roughness

Mangesh R.Phate, Dr. V.H.Tatwawadi [14], based on a new model formulation approach using Response Surface Methodology ( RSM) in ferrous and nonferrous material convectional turning (CT). The details obtained from the actual location where the real work is carried out. For the data collection tion, random experimentation plan focused on the industrial interests was considered. Operator data, tool data, workpiece data, cutting process parameters, system data and environmental parameters are the different independent parameters considered in this study, while the dependent parameter is surface quality achieved during the convectional turning process Optimization of scheduled servicing functions of passenger cars using a mathematical modelling approach.

J.P. Modak, K.SDixit, M. P. Singh. (2012) (English version) To simulate the scheduled servicing process for passenger cars, a generalised field data base model was created. They had found that parameters of vehicle design such as air philtre accessibility, fuel philtre \& oil philtre have maximum impact on the cycle time of the passenger cars' scheduled operation. And the challenging part in disassembling, Formulation of Field Data Based Model for Productivity Improvement of an Enterprise Manufacturing Tractor Axle Assembly: an Ergonomic Approach
Manish Bhadke, Dr.K.S.Zakiuddin. The key slogan of FDBM for the axle assembly process is to improve machine efficiency by rectifying or modifying inputs to improve production. It's found that decreased use of human efforts The job contains much of the ergonomic parameters and other parameters specific to the workplace that will influence the axle assembly mechanism 's efficiency. Mathematical Modelling and Simulation of Field Data based Model for Civil Activity

Paper tells about the use of contemporary techniques for the purpose of analysis, compression and generic approach for the FDMM of any Man Machine Device. Around it. The corrective action will be agreed upon once the vulnerabilities are identified. The basic application of the activities of Civil Engineering is discussed. The present analyzed results of few of the positive exercise "Field Data Based Modeling".

\section{VII- CONCLUSION}

Here It is shown that the dependent and independent variables involved were high so that they were reduced using dimensional analysis \& pi words evaluated.

The Buckingham pi theory is used to compare dimensional equations in order to find a common variable between dependent and independent terms.

A mathematical relationship is established between output parameters and input. The algebraic similarities include that increasing input variables must be maximum or minimum in order to maximise output variables. After the model is formulated, it is possible to refine the entire operation. The model would be useful for any manufacturing industry to pick optimised inputs in order to obtain targeted responses.

\section{REFERENCES}

[1] J.P.Modak and A.R.Bapat, -Various Experiences of a Human Powered Flywheel Motorl.Human Power (Technical Journal of IHPV) No54, Spring 2003, pp 21 23.

[2] K.S.Zakiuddin and J.P.Modak, - Formation of Approximate Generalised Experimental Data Based Model for a Fodder Choper Energised by Human Powered Flywheel Motorl, International Journal of Agricultural Engineering, Vol. 3, No. 2, October 2010, pp. 251-257.

[3] H.Schenek,Jr, - Theories of Engineering Experimentation\| McGraw Hill 1961. 
[4] Phate, M.R., Tatwawadi, V.H., Modak, J.P., Formulation Of A Generalized Field Data Based Model For The Surface Roughness Of Aluminum 6063 In Dry Turning Operation. New York Science Journal; 5(7),38-46 (2012)

[5] Tatwawadi, V.H., Modak, J.P., Chibule, S.G., Mathematical Modeling and simulation of working of enterprise manufacturing electric motor, International Journal of Industrial Engineering, 17(4), 341-35 (2010)

[6] J.P.Modak, K.S. Zakiuddin, "Mathematical modeling and simulation of field data based model for civil activity," International Journal of Scientific \& Engineering Research, Volume 3, Issue 3, March-2012.

[7] Mangesh R. Phate, Chetan K.Mahajan, Mangesh L.Mote, Bharat V.Patil, HarshalG.Patil, "Investigation of Turning Process Using Field Data Based Approach in Indian Small Scale Industries", International Journal of Research in Mechanical Engineering \& Technology,

[8] K.S. Dixit1, J.P. Modak, M. P. Singh, Optimization of scheduled servicing functions of passenger cars using a mathematical modeling approach", International Journal of Advances in Engineering Research (IJAER) 2012, Vol. No. 3, Issue No. IV, April

[9] Rupesh Patil, Gajanan K. Awari and Mahendra P. Singh, "Formulation of Mathematical Model and Neural Network Analysis of Scheffler Reflector", VSRD International Journal of Mechanical, Auto. \& Prod. Engg. Vol. 1 (1), 2011

[10] Satya Prakash Mishral, Parbat D.K, “Sensitivity analysis of multi parameter mathematical model in reinforced concrete construction ",international journal of civil and structural engineering Volume 3, No 1, 2012

[11] Sachin G Mahakalkar, Dr. Vivek H Tatwawadi, Jayant P Giri, Dr. J. P. Modak, "Corrugated box production process optimization using dimensional analysis and response surface methodology",[IJESAT] [International Journal of Engineering Science \& Advanced Technology] Volume-3, Issue-3, 96-105. 